Claremont Colleges

Scholarship@ Claremont

WM Keck Science Faculty Papers

W.M. Keck Science Department

3-1-1995

\title{
Dynamic Diseases in Neurology and Psychiatry
}

John Milton

Claremont McKenna College; Pitzer College; Scripps College

Deborah Black

\section{Recommended Citation}

Milton, John, and Deborah Black. "Dynamic diseases in neurology and psychiatry." Chaos 5.1 (1995): 8-13. DOI: 10.1063/1.166103

This Article is brought to you for free and open access by the W.M. Keck Science Department at Scholarship @ Claremont. It has been accepted for inclusion in WM Keck Science Faculty Papers by an authorized administrator of Scholarship @ Claremont. For more information, please contact scholarship@cuc.claremont.edu. 


\title{
Dynamic diseases in neurology and psychiatry
}

\author{
John Milton \\ Department of Neurology and Committee on Neurobiology, MC-2030, The University of Chicago Hospitals, \\ 5841 South Maryland Avenue, Chicago, Illinois 60637, and Center for Nonlinear Dynamics, McGill \\ University, Montréal, Québec, Canada
}

Deborah Black

Départment de Neurologie, Hôpital Hôtel Dieu, Montréal, Québec, Canada

(Received 16 May 1994; accepted for publication 21 September 1994)

Thirty-two (32) periodic diseases of the nervous system are identified in which symptoms and/or signs recur. In 10/32, the recurrence of a symptom complex is one of the defining features of the illness, whereas in 22/32 oscillatory signs occur in the setting of an ongoing nervous system disorder. We discuss the possibility that these disorders may be dynamic diseases. (C) 1995 American Institute of Physics.

\section{INTRODUCTION}

The human nervous system is composed of a hierarchy of oscillatory processes. Self-sustained oscillations occur at the level of the single neuron, ${ }^{1,2}$ small collections of neurons, ${ }^{2-5}$ and in large neural populations. ${ }^{6,7}$ In addition, the behavior of the nervous system can be influenced by external "zeitgebers," such as daylight and seasonal cycles. $^{8-10}$ Thus, it should not be surprising to observe that many diseases of the nervous system also have oscillatory features. Indeed, recurrence is a defining feature of many neurological and psychiatric illnesses, including epilepsy, migraine, manic-depressive illness, and multiple sclerosis. The clinical significance of altered neural thythms in sleep, ${ }^{11}$ epilepsy, ${ }^{12}$ and depression ${ }^{10}$ is well recognized.

The importance of considerations of the temporal pattern of illness derives from theoretical insights into the nature of oscillatory phenomena. ${ }^{13-25}$ Mathematical studies have predicted that a single neurophysiological control mechanism, for example, a recurrent inhibitory loop, ${ }^{26}$ is capable of generating a variety of qualitatively different periodic rhythms, as well as irregular, noise-like fluctuations. The temporal pattern that is seen depends on the value of certain critical control parameters. In patients with nervous system disorders, two patterns of recurrent disease can be recognized clinically: ${ }^{18,20,23,27}$ (1) regular, possibly periodic recurrences; and (2) irregular, seemingly random recurrences. Is it possible that the temporal pattern of some of these disease, herein referred to as dynamic diseases, reflect an abnormal setting of a critical neurophysiological parameter, such as neural conduction time ${ }^{13,29}$ The significance of identifying a dynamic disease is that it may be possible to develop therapeutic strategies based on manipulation of the critical control parameter(s). $13,15,18,20,28$

The hallmark of a dynamic disease is a sudden, qualitative change in the temporal pattern of an illness, in response either to a therapeutic maneuver or to some endogenous factor, which presumably changes a critical control parameter. ${ }^{13-15,20,29,30}$ It is not currently possible to apply this approach to detect a dynamic disease, since the nature of the relevant control parameters is not known. Here we identify "periodic" diseases in neurology and psychiatry. This represents a first step toward determining those diseases that are potential candidates for dynamic diseases. It is possible that longitudinal study of the diseases may help identify critical control parameters that may be susceptible to therapeutic modification.

\section{METHODS}

A computer-assisted (MEDLINE) search of the English and French literature from 1966 to 1994 identified $\sim 4500$ papers, which dealt with periodic phenomena in clinically related neuroscience. By restricting the search to human disease and specifically excluding the term "circadian rhythm," the number of papers was reduced to $\sim 300$. All of these papers were reviewed.

\section{RESULTS}

\section{A. "Periodic" diseases}

Thirty-two diseases were identified in which symptoms and/or signs recurred periodically. These disorders could be grouped into two broad categories: (1) Group I: diseases that were characterized by the recurrence of certain symptoms (10/32 diseases; Table I); and (2) group II: oscillations that appear in the context of an ongoing nervous system disease (22/32 diseases; Table II). In group I diseases, no anatomical/ biochemical lesion has yet been identified that causes the recurrent symptoms. In between the episodes, the patient is well, unless the attack itself causes a structural lesion as, for example, in patients with multiple sclerosis. On the other hand, in group II diseases, an anatomical/biochemical has been identified or is presumed to exist. These abnormalities typically occur within the relevant neural feedback loop(s). Persistence of symptoms in the setting of a chronic disability is the hallmark.

Reports of patients with periodic diseases take four forms: (1) case reports; (2) analysis of patient diaries; (3) longitudinal studies of institutionalized patients; and (4) laboratory monitored time series.

\section{B. Case reports}

The most common manner in which a periodic disease is brought to the attention of the medical community is in the 
TABLE I. Recurrent nervous system disease.

\begin{tabular}{lll}
\hline Disease & Time series & References \\
\hline Behavioral & & \\
\hline Manic-depressive illness & Yes & $10,31-37$ \\
Cycloid psychoses & No & 38 \\
Kleine-Levin syndrome & Yes & $39-41$ \\
Neurological & & \\
\hline Epilepsy & Yes & $27,42-45$ \\
Migraine and its variants & Yes & $46-47$ \\
Multiple sclerosis & Yes & $48-49$ \\
Periodic ataxia & No & $50-52$ \\
Periodic hypothermia & No & 53 \\
Periodic dystonic choreoathetosis & No. & $54-56$ \\
Periodic paralysis & No & $57-58$ \\
\hline \hline
\end{tabular}

form of a case report. As might be anticipated, the publication of a case report overemphasizes patients with unusual and rare clinical presentations. The observation of the appearance or disappearance of a rhythmic process following a discrete lesion in the nervous system is evidence that this part of the nervous system is somehow involved in the genesis of the dynamic process. This tight correlation between clinical observation and anatomical abnormality is most clear in the setting of disorders of ocular motility ${ }^{65-72}$

In many cases the clinical phenomena are so fascinating that they warrant publication. For example, Paschalis et al. ${ }^{35}$ describe a 78 yr old man who developed rapid mood oscillations, ranging from mania to depression. Each phase lasted approximately $24 \mathrm{~h}$, and the cycles persisted for months. While depressed, he felt hopeless, worthless, and was inactive; while manic; he became jocular, overactive, and optimistic. The switch between the behavioral states always occurred during the daytime. However, the time of day the switch occurred varied in a predictable manner. Over 5-6 days, the switch time would be advanced by $1-2 \mathrm{~h}$ each cycle. Once the switch time was in early morning, the next switch time was advanced by $12-48 \mathrm{~h}$, so that the subsequent switch occurred in late afternoon or evening.

\section{Diaries}

Often patients with recurring symptoms come to the attention of physicians when the patient and/or their family members keep a diary of their illness. For example, the letters of Vincent Van Gogh to his brother Theo ${ }^{104}$ provide a diary of the episodic psychoses to which he was subject all his adult life and which informed his creative genius. The influence of an exogenous toxin, probably absinthe, may have modified the timing, as well as the content of his periodic psychoses.

Events documented in a diary are clearly of great significance to the author. Thus, it is surprising that so little has been written concerning the periodicity of pain. An exception is the study of Kaufmann et al..$^{105}$ on the timing of acute myocardial infarction pain. Nearly one-half (34/74) of the patients experienced their chest pain at extremes of the ACTH-cortisol excretion cycle, i.e., between 8 and 10 a.m. and between 8 and 10 p.m.
TABLE II. Oscillations in setting of neurological disease.

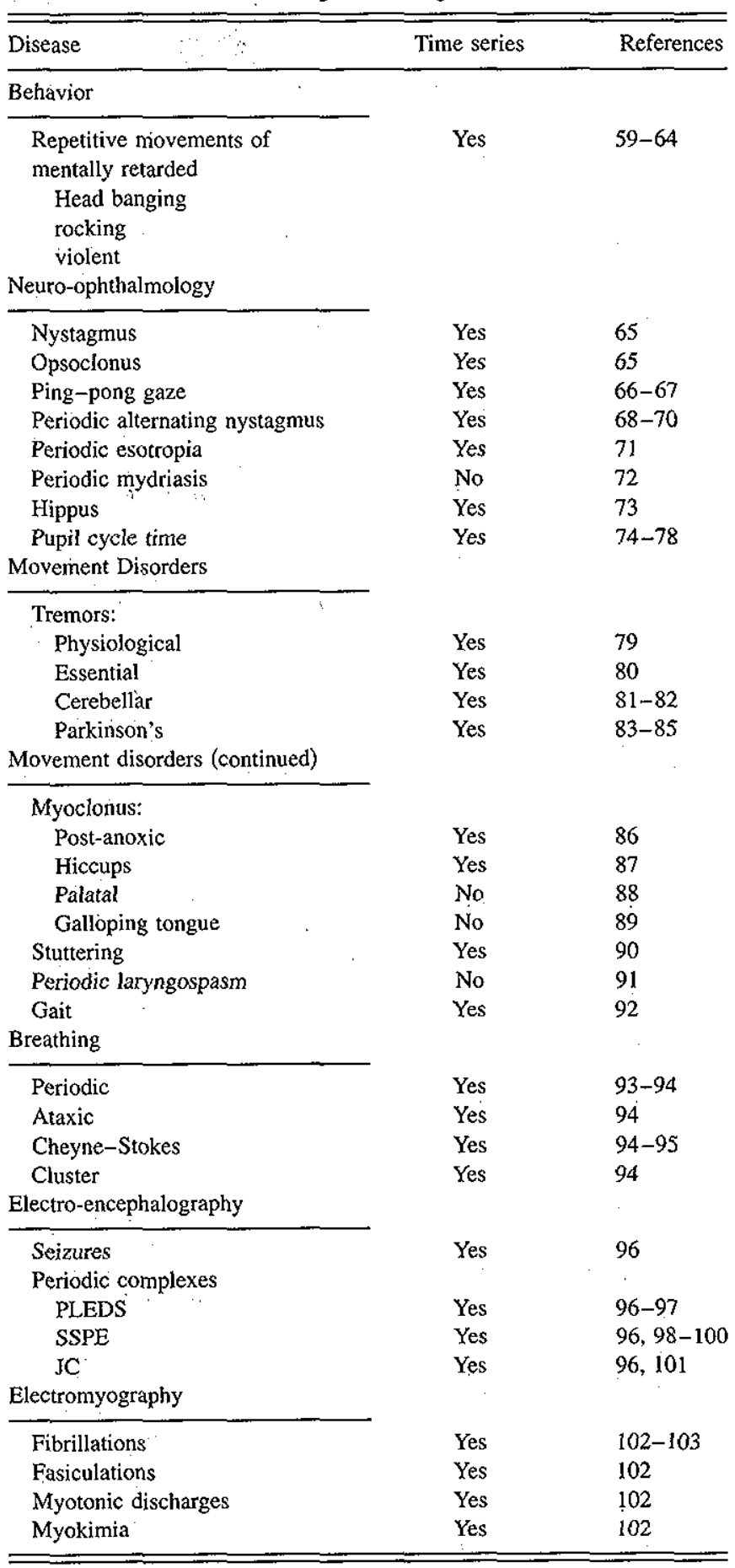

Lengthy diaries of recurring neurological and psychiatrical symptoms have been published: epilepsy, ${ }^{27,42-45}$ headache, ${ }^{47}$ and affective disorders. ${ }^{10,34-36}$ Recently, these diaries have been subjected to time series analyses. For example, seizure diaries have been analyzed for evidence of an underlying deterministic mechanism with the aim of predicting the time of recurrence of the next seizure. . $^{30,32-33}$

Figure 1(a) shows a seizure diary and Fig. 1(b) a headache diary for two patients in our clinical practices. Although both patients felt that there was a definite periodic flavor to their illness, the time series are not clearly periodic. Indeed, 


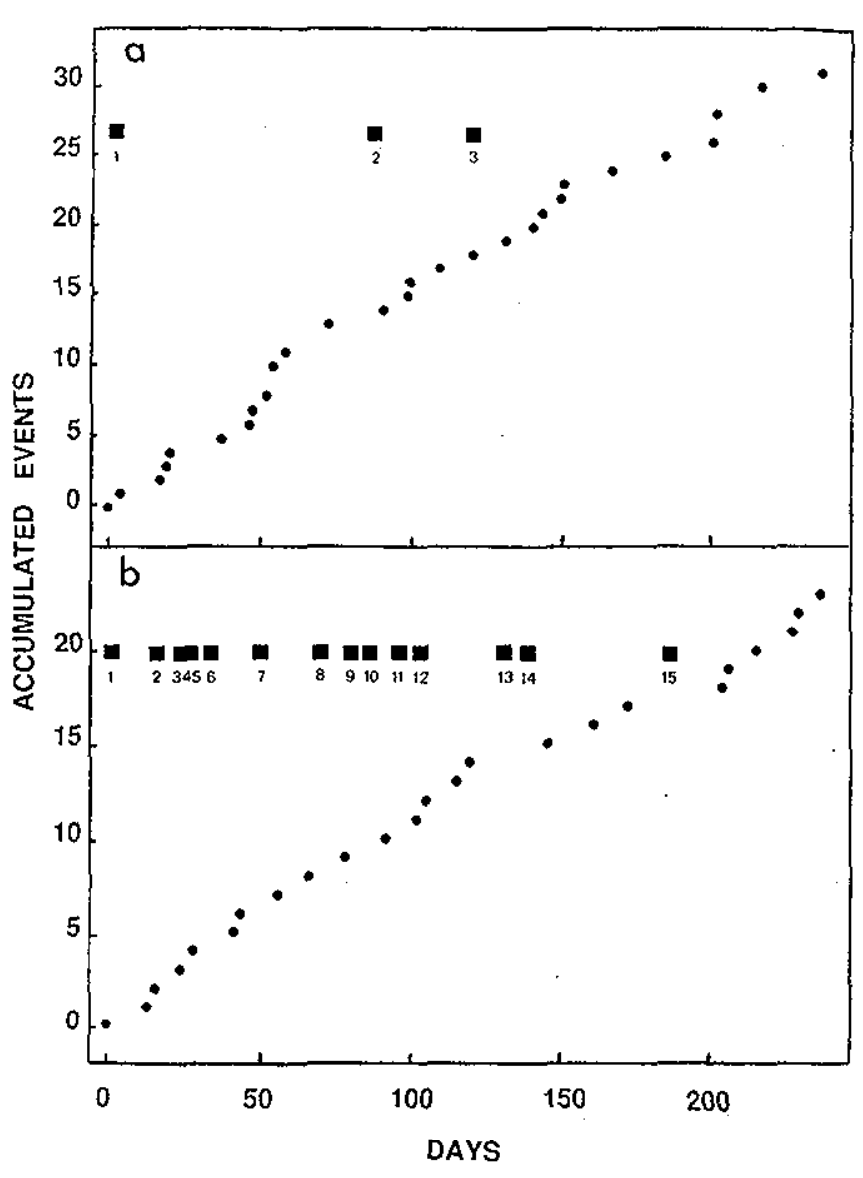

FIG. 1. Accumulated events (O) as a function of time for a (a) $17 \mathrm{yr}$ old boy with seizures, and (b) a 46 yr old female with headaches. In (a) the events numbered 1 and 3 correspond to a change in medication and 2 to a headache. In (b) events $1,8,10$, and 11 correspond to medication changes, 2, 6, $7,9,12,13$, and 15 to the onset of menses, and $3,4,5$, and 14 to concurrent illness.

the approximate linearity of a plot of the accumulated number of events versus time is more suggestive of a random (Poisson) process. ${ }^{27}$ However, over the course of the diary, both patients experienced concurrent illnesses, as well as changes in their medications. It is possible that these perturbations may obscure the periodic trends.

\section{Institutionalized patients}

Longitudinal studies of patients confined to institutions because of severe medical problems provide an excellent opportunity to study rhythmic phenomena. Since patients live in a controlled environment and concurrent events can be well documented, the response of the rhythm to exogenous perturbations can be recorded. For example, patients with epilepsy who were living on "epileptic communes" or "farms" at the turn of the century provide the best time series for seizure recurrence prior to the introduction of effective anticonvulsant medications. ${ }^{42,44}$ With the development of modern medical therapies, studies of institutionalized patients have been largely limited to two patient groups: (1) severely mentally handicapped children, and (2) patients with psychiatric illness.
Stereotyped motor behaviors, such as rocking, head banging, arm flapping, and self-mutilation occur in severely mentally handicapped children. ${ }^{59-64}$ The clinical significance of these behaviors, results from their interference with caretaker management to the loss of digits, and even blindness from self-mutilation. Recently, it has been observed that these motor behaviors recur with surprising regularity, with periods varying from $90 \mathrm{~min}$ to $8 \mathrm{~h}$. Monthly and circaannual cycles have also been reported. In some children, the frequency and tempo of the stereotyped movements can be modified by playing strongly rhythmic marching music during the rocking episodes. ${ }^{62}$

Kleine-Levin syndrome, a recurrent disorder of unknown etiology occurring in adolescent boys, offers another fascinating glimpse into periodic behavioral phenomena. ${ }^{39-41}$ Affected boys abruptly develop drowsiness, lethargy, confusion, and a craving for carbohydrates, sometimes accompanied by sexual preoccupations and inappropriate sexual behavior. Episodes last days to weeks and resolve spontaneously. Afterward, patients do not fully recall their behavior.

Perhaps the most exciting observations concerning a periodic disease have been made on patients with "rapidcycling" manic-depressive illness. ${ }^{10,31-37}$ Such patients oscillate between mania and depression with each phase lasting about $24 \mathrm{~h}$. Recent interest has focused on the nature of the "switch" between the two behavioral states. Just before the switch patients may experience marked insomnia and decreased REM sleep, raising the possibility that brain monoamine metabolism may play a role in the switch process.

\section{E. Time series}

Thirty-six percent $(36 \%)$ of the papers describing periodic diseases included a presentation of the raw time series. In $17 \%$, only a statistical description of the observations (e.g., mean period, minimum/maximum interval) was presented. However, in $37 \%$ of the papers, no data were presented to either substantiate the recurring nature of the illness or describe its characteristics.

Raw time series data were typically presented for phenomena that recur rapidly (i.e., seconds) and that could be monitored with electrophysiological techniques. Examples include periodic phenomena in the electroencephalogram and a variety of neuro-ophthalmologic and movement disorders (Table II). In these cases, the time series were characteristically $\leqslant 1$ minute, and were chosen to illustrate the phenomena under consideration. Notably, a number of raw time series lasting minutes to years for recurring diseases suitable for analyses have been published: epilepsy, ${ }^{27,42-45}$ headache, ${ }^{47}$ affective disorders, ${ }^{10,34-36}$ Kleine-Levin syndrome, ${ }^{39-41}$ and breathing patterns in patients with acute brain damage. ${ }^{93}$

Overnight video-EEG monitoring provides an excellent, but largely unexploited, opportunity to study sleep-related phenomena. An example is periodic leg movement during sleep, which consist of bursts of rhythmic leg movements occurring at multiple intervals throughout the night. ${ }^{11}$ These 
movements show considerable night-to-night variations within the same subject.

\section{F. Induced changes in periodic diseases}

Qualitative changes in disease dynamics have been extensively described in patients with epilepsy and with sleep and affective disorders. These diseases are presently the best candidates for dynamic diseases of the nervous system.

Seizures can be induced in certain patients by a variety of stimuli, including hyperventilation and photic stimulation. ${ }^{106}$ The period of the epileptic complexes in subacute sclerosing panencephalitis (SSPE) can be changed as body temperature is altered. ${ }^{100}$ Attention and arousal also appear to play a role in modifying the frequency of epileptic spike-and-wave discharges. ${ }^{107}$ When children with petit mal epilepsy became bored (for example, during inactivity), they had many more seizures than when their attention was engaged (for example, during IQ testing or a formal interview). Moreover, the frequency of epileptic discharges in the EEG during school exercises was approximately the same as during inactivity! These observations underscore the role of context in producing the variability in a periodic phenomena.

In patients with affective disorders, periods of mania and depression can be precipitated by, respectively, tricyclic antidepressants ${ }^{108-110}$ and seasonal changes in ambient light levels. ${ }^{10,111}$ The period of rapid-cycling manic-depressive illness can be changed by tricyclic antidepressants, ${ }^{18,108-110}$ and in some patients the oscillation can be abolished with lithium. Stoddard et al..$^{112}$ describe a $39 \mathrm{yr}$ old woman whose switch between mania and depression could be triggered by significant events in the patient's personal life, such as birthday, holidays, or therapy sessions with her husband.

\section{G. Treatment strategies}

When symptoms cause significant morbidity, it becomes necessary to develop a therapeutic strategy. Given that the underlying mechanism for a periodic disease is generally unknown, it would be anticipated that this can be a foreboding task. Nonetheless, patients and their physicians have often been able to arrive at effective treatments.

Several treatment strategies have emphasized the use of a discrete stimulus applied at a critical time. An example is the nonpharmacological treatment of patients with epilepsy. Caretakers of patients with epilepsy sometimes note that seizures can be aborted by startling the patient with a sudden noise or shaking. In the late 1960s, investigators developed an automated version of this strategy by constructing a special headset worn by the patient: one earphone monitored the EEG, and when a seizure was detected, triggered a loud noise in the contralateral ear. ${ }^{113}$ By carefully tuning the intensity of the sound and its timing with respect to seizure onset, they were able to achieve seizure control in a number of otherwise difficult to manage patients with epilepsy. Unfortunately, this trial and error approach proved too time consuming for the method to be generally applicable. A more modern version of this approach is vagal stimulation. ${ }^{114,115}$ Other examples include exposure to light to treat jet lag ${ }^{111}$ and seasonal affective disorder. ${ }^{10,111,116}$
More commonly, the treatment of periodic disorders has focused on pharmacological strategies. From a dynamical disease standpoint, "such approaches can be thought of as a "shotgun" method to alter control parameters. Examples include the use of lithium to dampen fluctuations in mood, ${ }^{117}$ anticonvulsant medications to prevent seizures, melatonin to modify jet lag, ${ }^{111}$ and the combination of thyroid hormone, benzodiazepines, and vitamin B12 to reset a free-running sleep wake cycle. ${ }^{118}$ An example of a nonpharmacological approach to alter a control parameter is the addition of weights to a limb in a patient with cerebellar disease to decrease the oscillations of an intention tremor. ${ }^{82}$

\section{DISCUSSION}

We have shown that there are at least 32 periodic diseases in psychiatry and neurology. These disorders arise at every level of the nervous system: muscle, nerve, spinal cord, brainstem, and cortex. Clinical experience suggests that patients with periodic recurrences in their symptoms can be especially refractory to treatment by traditional methods (for example, catamenial epilepsy ${ }^{119}$ ). It is possible that a careful study of disease dynamics might shed light onto the etiology of these disorders and how they can be best managed.

It is not unreasonable to hope that the recent mathematical advances into the nature of oscillatory processes might provide insights into the management of periodic diseases. For this to be fruitful, a necessary first step is that the time series be well enough described to permit analyses. A problem is that the clinical use of the term "periodic" differs from its mathematical meaning. Periodic diseases typically do not recur with clock-like regularity, but "every so often" or "every once in a while."

There are two possible explanations for the irregularity in the recurrence of symptoms and/or signs in periodic diseases. First, the periodicity of the disease may have been obscured by various randomly occurring endogenous and exogenous factors. Moreover, the behavioral and symptomatic measurements employed by physicians in the bedside assessment of a patient may be too crude to detect subclinical periodic oscillations. Second, it is possible that the disease process is inherently irregular. Time series methods to distinguish between these two possibilities are available. ${ }^{120}$ However, these methods are currently of limited clinical value, since they require long time series that are impractical to obtain, particularly for those diseases in which the symptoms recur infrequently (e.g., monthly or yearly).

Social events and context can cause important perturbations in periodic phenomena in humans and animals. In a fascinating study of ten lizards housed in a group cage, Regal and Connolly ${ }^{121}$ observed that the "omega lizard," at the bottom of the dominance hierarchy, desynchronized its sleep-wake-feeding thythm from the other lizards in the cage, presumably as an adaptation to avoid aggression and conflict over food. Similar observations have been made in rats. Such perturbations are difficult to quantitate and are rarely described in clinical time series. This further underscores the difficulty in interpreting irregular time series.

An underlying mechanism for the recurrent diseases becomes conceptually plausible when a qualitative change in 
temporal pattern occurs in response to a therapeutic maneuver can be identified. Such changes have indeed been observed in a number of periodic diseases (see Sec. III D), and identify such diseases as dynamic diseases. Since a relatively short time series before and after the perturbation are all that is required to demonstrate a change in temporal pattern, it should be possible for physicians to readily identify such phenomena. Moreover, a control parameter, which potentially can be manipulated to therapeutic advantage, has necessarily been identified.

The temporal dimension of illness continues to receive little attention from physicians, whose major focus is the molecular pathophysiology and pharmacological treatment of disease. However, it is conceivable that the beneficial effects of a drug in the treatment of a periodic disease could be overlooked if proper attention is not given to details concerning, for example, the timing of drug administration. ${ }^{105}$ In addition, it is possible that nonpharmacological therapeutic approaches may be as useful (as, for example, in the treatment of epilepsy). The challenge to the clinician will be to identify those patients in whom considerations of disease dynamics are necessary in order to formulate a treatment strategy.

\section{ACKNOWLEDGMENTS}

We gratefully acknowledge the invaluable assistance of the library staff at Hôtel Dieu Hospital. This work was supported by grants obtained from the National Institutes of Mental Health (NIMH) and the North Atlantic Treaty Organization (NATO).

${ }^{1}$ L. R. Silva, Y. Amital, and B. W. Connors, Science 251, 432 (1991).

${ }^{2}$ R. Llinás, Science 242, 1654 (1988).

${ }^{3}$ R. D. Traub, R. Miles, and R. K. S. Wong, Science 243, 1319 (1989).

${ }^{4}$ J. C. Snith et al., Science 254, 726 (1991).

${ }^{5}$ M. Von Krosigk, T. Bal, and D. A. McCormick, Science 261, 361 (1993).

${ }^{6}$ M. Steraide, P. Gloor, R. R. Llinás, F. H. Lopes da Silva, and M.-M. Mesulam, Epilepsia 76, 481 (1990)

${ }^{7}$ M. Steriade, D. A. McCormick, and T. J. Sejnowski, Science 262, 679 (1993).

${ }^{8}$ C. A. Czeisler et al., Science 244, 1328 (1989).

${ }^{9}$ D. D. Ginty, J. M. Kornhauser, M. A. Thompson, H. Bading, K. E. Mayo, J. S. Takahashi, and M. E. Greenberg, Science 260, 238 (1993).

${ }^{10} \mathrm{~T}$. A. Wehr and F. K. Goodwin, in Circadian Rhythms in Psychiatry (Boxwood, Pacific Grove, CA, 1983).

"S. Sheldon, J.-P. Spire, and H. Levy, Pediatric Sleep Medicine (Saunders, Philadelphia, 1992).

${ }^{12} \mathrm{E}$. Wylie in The Treatment of Epilepsy: Principles and Practice (Lea \& Febinger, Philadelphia, 1993).

${ }^{13}$ M. C. Mackey and L. Glass, Science 197, 287 (1977).

${ }^{14}$ L. Glass and M. C. Mackey, Ain. NY Acad. Sci. 316, 214 (1979).

${ }^{15} \mathrm{U}$. an der Heiden and M. C. Mackey, J. Math. Biol. 16, 7.5 (1982).

${ }^{16}$ M. C. Mackey and U. an der Heiden, Funkt. Biol. Med. 1, 156 (1982).

${ }^{17} \mathrm{~L}$. Rensing, U. an der Heiden, and M. C. Mackey, Temporal Disorder in Human Oscillatory Systems (Springer-Verlag, New York, 1987).

${ }^{18}$ M. C. Mackey and J. G. Milton, Ann. NY. Acad. Sci. 504, 16 (1987).

${ }^{19}$ L. Glass and M. C. Mackey, From Clocks to Chaos: The Rhythms of Life (Princeton University Press, Princeton, NJ, 1988).

${ }^{20}$ J. G. Milton et al., J. Theor. Biol. 138, 129 (1989).

${ }^{21}$ J. G. Milton and M. C. Mackey, J. R. Colloid. Phys. London 23, 236 (1989).

${ }_{22}$ J. G. Milton et al., Biomed. Biochim. Acta 49, 697 (1990).

${ }^{23}$ M. C. Mackey and J. G. Milton, Comments Theor. Biol. 1, 299

${ }^{24}$ L. Glass, Chaos 1, 247 (1991).

${ }^{25}$ A. Asachenkov, G. Marchuk, R. Mohler, and S. Zuev, Disease Dynamics (Birhäuser, Boston, 1994)
${ }^{26}$ M. C. Mackey and U. an der Heiden, J. Math. Biol. 19, 211 (1984).

${ }^{27}$ J. G. Milton et al., Epilepsia 28, 471 (1987).

${ }^{28}$ J. G. Milton, S. A. Campbell, and J. Bélair, J. Biol. Sys. (in press).

${ }^{29}$ L. Glass, A. Beuter, and D. Larocque, Math. Biosci. 90, 111 (1988).

${ }^{30}$ A. Longtin and J. G. Milton, Math. Biosci. 90, 183 (1988).

${ }^{31}$ W. E. Bunney et al., Ann. Int. Med. 87, 319 (1977).

${ }^{32}$ S. M. Hanna, F. A. Jenner, and L. P. Souster, Br. J. Psychiat. 149, 229 (1986).

${ }^{33}$ D. J. King, S. A. M. Salem, and N. S. Meimary, Br. J. Psychiat. 135, 190 (1979).

${ }^{34}$ G. Nikitopoulou and J. L. Crammer, Br, Med. J. 1, 1311 (1976).

${ }^{35}$ C. Paschalis, A. Pavlou, and A. Papadimitriou, Br. J. Psychiat. 137, 332 (1980).

${ }^{36}$ T. A. Wehr et al., Arch. Gen. Psychiat. 39, 559 (1982).

${ }^{37}$ S. Zisook, J. Nerv. Ment. Dis. 176, 53 (1988).

${ }^{38} \mathrm{~K}$. Leonhard, J. Ment. Sci. 107, 633 (1961).

${ }^{39} \mathrm{C}$. Billard et al., Arch. France Ped. 35, 424 (1978).

${ }^{40} \mathrm{H}$. Garland, D. Sumner, and P. Fourman, Neurology 18, 116I (1965).

${ }^{41} \mathrm{M}$. Billiard, C. Guilleminault, and W. C. Dement, Neurology 25, 436 (1975).

${ }^{42}$ R. Almqvist, Acta Psych. Neurol. Scand. (Suppl. 105) 30, 1 (1955).

${ }^{43} \mathrm{G}$. W. Frank et al., Physica D 56, 427 (1990).

${ }^{44}$ G. M. Griffiths and J. T. Fox, Lancet 409 (1938).

${ }^{45} \mathrm{~L}$. Iasemidis et al., Epilepsy Res. 17, 81 (1994).

${ }^{46}$ G. C. Manzoni et al., Eur. Neurol. 20,88 (1981).

${ }^{47}$ P. O. Osterman et al., Upsala J. Med. Sci. Suppl. 31, 23 (1980).

${ }^{48} \mathrm{~B}$. Weinshenker and G. Ebers, Can. J. Neurol, Sci. 14, 255 (1987).

${ }^{49} \mathrm{~B}$. Weinshenker et al., Brain 112, $1419(1989)$.

${ }^{50}$ R. W. Baloh and A. Winder, Neurology 41, 429 (1991).

${ }^{51}$ W. DeCastro and J. Campbell, J. Am. Med. Assoc. 200, 892 (1967).

${ }^{52}$ G. J. Hankey and S. S. Gubbay, Med. J. Austral. 150, 277 (1989).

${ }^{53}$ R. H. Fox et al., Br. Med. J. 2, 693 (1973).

${ }^{54}$ J. W. Lance, Ann. Neurol. 2, 285 (1977).

${ }^{55}$ L. A. Mount and S. Reback, Arch. Neurol. Psychiat. 44, 841 (1940).

${ }^{56}$ R. N. Richards and H. J. M. Barnett, Neurology 18, 461 (1968).

${ }^{57}$ T. Johnson, Dan. Med. Bull. 28, 1 (1981).

${ }^{58}$ R. B. Layzer, R. E. Lovelace, and L. P. Rowland, Arch. Neurol. 16, 455 (1967).

${ }^{59} \mathrm{M}$. H. Lewis et al., Am. J. Mental Defic. 85, 601 (1981).

${ }^{60} \mathrm{R}$, Brusca, Am. J. Mental Defic. 89, 650 (1985).

${ }^{61}$ A. Meier-Koll and P. Pohl, Int. J. Chronobiol. 6, 191 (1979).

${ }^{62}$ E. A. Stevens, Am. J. Mental Defic. 76, 76 (1971).

${ }^{63}$ W. B. Quay, Chronobiologia 2, 243 (1975).

${ }^{64}$ M. G. Wade, Am. J. Mental Defic. 78, 262 (1973).

${ }^{65}$ N. R. Miller, in Walsh and Hoyt's Clinical Neuro-Ophthalmology (Wiltiams \& Wilkins, Baltimore, MD, 1985).

${ }^{66} \mathrm{H}$. Ishikawa, S. Ishikawa, and K. Mukuno, Neurology 43, 1067 (1993).

${ }^{67}$ E. F. Masucci et al., Ann. Ophthalmol. 13, 1123 (1981).

${ }^{68}$ R. W. Baloh, V. Honrubia, and H. R. Konrad, Brain 99, 11 (1976).

${ }^{69}$ M. E. Norre and T. Puls, Acta Oto-Rhino-Laryngol. Belg. 35, 198 (1981),

${ }^{70}$ P. Rudge and J. Leech, J. Neurol. Neurosurg. Psychiat. 39, 314 (1976).

${ }^{71}$ B. T. Troost et al., Am. J. Ophthalmol. 91, 8 (1981).

${ }^{72}$ M. Hallett and D. G. Cogan, Arch. Ophthalmol. 84, 130 (1970).

${ }^{73}$ L. Stark, F. W. Campbell, and J. Atwood, Nature 182, 857 (1958).

${ }^{74}$ S. D. Miller and H. S. Thompson, Br. J. Ophthalmol, 62, 495 (1978).

${ }^{75}$ J. G. Milton et al., Am. J. Ophathalmol. 105, 402 (1988).

${ }^{76}$ A. Longtin and J. G. Milton, Bull. Math. Biol. 51, 605 (1989).

${ }^{77}$ A. Longtin and J. G. Milton, Biol. Cybern. 61, 51 (1989).

${ }^{78} \mathrm{~J}$. G. Milton and A. Longtin, Vision Res. 30, 515 (1990).

${ }^{79}$ O. Lippold, Sci. Am. 224, 65 (1971).

${ }^{80}$ W. C. Koller and N. Biary, Neurology 34, 221 (1984).

${ }^{81} \mathrm{~J}$. Bruce and C. McLellan, Lancet 1, 1221 (1980).

${ }^{82}$ R. L. Hewer, R. Cooper, and M. H. Morgan, Brain 95, 759 (1972).

${ }^{83}$ A. Beuter et al, Exp. Neurol. 110, 228 (1990).

${ }^{84} \mathrm{~A}$. Beuter and K. Vasilakos, Chaos 5, 35 (1995).

${ }^{85} \mathrm{~S}$. Toth, P. Zarand, and L. Lazar; Acta Neurochir. Suppl. 21, 25 (1974).

${ }^{86}$ P. J. Wolf, Neurol. 215, 39 (1977).

${ }^{87}$ W. A. Whitelaw and J-Ph. Derenne, Chaos 5, 14 (1995).

${ }^{88}$ J. Lapresle, J. Neurol. 220, 223 (1979).

${ }^{39}$ J. R. Keane, Neurology 34, 251 (1984).

${ }^{90}$ R. R. Martin, L. J. Johnson, G. M. Siegel, and S. K. Haroldson, J. Speech Hear. Res. 28, 487 (i985).

${ }^{91}$ J. Cambier et al.; Rev. Neurol. (Paris) 139, 531 (1983). 
${ }^{92}$ R. D. Adams and M. Victor, Principles of Neurology (McGraw-Hill, Toronto; 1985).

${ }^{93}$ J. B. North and S. Jennett, Arch. Neurol. 31, 338 (1974).

${ }^{94} \mathrm{~F}$. Plum and J. B. Posner, The Diagnosis of Stupor and Coma (Davis, Philadelphia, 1980).

${ }^{95}$ A. C. Guyton, J. W. Crowell, and J. W. Moore, Am. J. Physiol. 187, 395 (1956).

${ }^{96}$ E. Niedermeyer and L. da Silva, Electroencephalography: Basic Principles, Clinical Applications and Related Fields (Urban \& Schwarzenberg, Baltimore, 1987).

${ }^{97}$ A. Janati, M. Z. Chesser, and M. M. Husain, Clin. Electroenceph. 17, 36 (1986).

${ }^{98}$ G. G. Celesia, Electroenceph. Clin. Neurophysiol. 35, 293 (1973).

${ }^{99}$ B. M. Evans, Electroenceph. Clin. Neurophysiol. 39, 587 (1975).

${ }^{100}$ D. E. Farrell, A. Starr, and J. M. Freeman, Electroenceph. Clin. Neurophysiol. 30, 415 (1971).

${ }_{101}$ P. Gloor, Ann. Neurol. 8, 341 (1980).

${ }^{102}$ J. Kimura, Electrodiagnosis in Diseases of Nerve and Muscle: Principles and Practice (Davis, Philadelphia, 1983).

${ }^{103}$ D. Purves and B. Sakmann, J. Physiol. 239, 125 (1974).

${ }^{104}$ R. R. Monroe, J. Nerv. Mental Disorders 166, 480 (1978).
${ }^{105}$ M. W. Kaufman et al., Psychosomatics 23, 1109 (1982).

${ }^{106}$ R. B. Aird, Epilepsia 24, 567 (1983).

${ }^{107} \mathrm{~J}$. Guey et al., Epilepsia 10, 441 (1969).

${ }^{108}$ B. Lerer et al., Br. J. Psychiat. 137, 183 (1980).

${ }^{109}$ S. G. Siris, H. R. Chertoff, and J. M. Perel, Am. J. Psychiat. 136, 341 (1979).

${ }^{110}$ T. A. Wehr and F. K. Goodwin, Arch. Gen. Psychiat. 36, 555 (1979).

111 A. J. Lewy and R. L. Sack, Proc. Soc. Exp. Biol. Med. 183, 11 (1986).

${ }^{112}$ F. J. Stoddard, R. J. Post, and W. E. Bunney, Br. J. Psychiat. 130, 72 (1977).

${ }^{113}$ F. M. Forster, Reflex Epilepsy, Conditional Reflexes and Behavioural Treatment (Thomas, Springfield, IL, 1975).

${ }^{114}$ A. R. M. Upton, Pacing Clin. Electrophysiol. 15, 1543 (1992).

${ }^{115}$ B. J. Wilder, Epilepsia 31, S1 (1990).

${ }^{116}$ A. Wirz-Justice, Prog. Drug Res. 31, 383 (1987).

${ }^{117}$ Y. A. Rosier, P. Brousolle, and M. Fontany, Ann. Medico-Psychol. 132, 389 (1974).

${ }^{118}$ B. Kamgar-Parsi, T. A. Webr, and J. C. Gillin, Sleep 6, 257 (1983).

${ }^{119}$ R. H. Mattson, J. M. Kamer, and J. A. Cramer, Epilepsia 22, 242 (1981).

${ }^{120}$ D. Kaplan, Physica D 73, 38 (1994).

${ }^{121}$ P. J. Regal and M. S. Connolly, Behavior 72, 171 (1980). 